\title{
A culpa é das estrelas?
}

Patrícia de Paula Aniceto, mestra em Literatura Brasileira pelo Centro de Ensino Superior de Juiz de Fora. Atualmente, está cursando isoladamente a disciplina "Representações da Memória" com a Prof. a .

Drª Nícea Helena Nogueira, no Doutorado da Faculdade de Letras da Universidade Federal de Juiz de Fora. Endereço eletrônico: patriciapaulaniceto@hotmail.com ou patricianiceto@yahoo.com.br

\section{Resumo:}

Considerando que a Literatura entrelaça um diálogo com as variadas mídias, este artigo tem como objetivo analisar a relação e a interação entre as seguintes mídias: Literatura, Cinema e Internet com enfoque na obra A culpa é das estrelas, de John Green, cuja primeira edição foi em 2012. Ainda hoje, é possível reconhecermos e identificarmos essa obra a partir de variadas formas e fontes. Partindo dessa análise, pretende-se apresentar - processo da criação, da reconstrução e da recepção da referida obra. Estas são as principais proposições que, aqui, discutiremos.

Palavras-chave: A culpa é das estrelas, John Green, Intermidialidade, Literatura, Cinema, Internet.

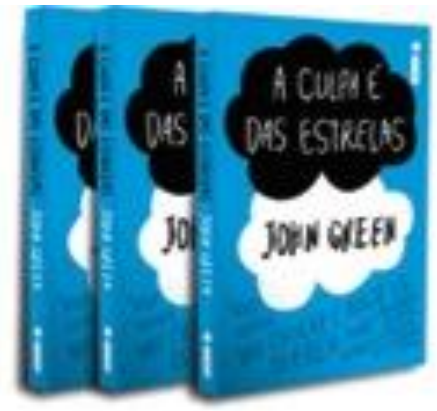

Fig. 1: Capa ilustrativa da obra A culpa é das estrelas, de John Green. Trad. Renata Pettengill. Rio de Janeiro: Intrínseca, 2012.

Considerando que a Literatura entrelaça um diálogo com as variadas mídias, este artigo tem como objetivo analisar a relação e a interação entre as seguintes mídias: Literatura, Cinema e Internet com enfoque na obra A culpa é das estrelas, de John Green. Partindo dessa análise, pretende-se apresentar o processo da criação, da reconstrução e da recepção da 
referida obra. Estas são as principais proposições que, aqui, discutiremos.

$\mathrm{Na}$ época da textualidade eletrônica, nos deparamos com o best-seller literário "A culpa é das estrelas", do escritor norteamericano John Green. O romance, cuja primeira edição foi em 2012, fez com que os adolescentes se sensibilizassem com o drama e com a história de amor dos jovens protagonistas Hazel e e Augustus Waters. Ela é uma paciente terminal e ele é um garoto que também passa a frequentar o Grupo de Apoio a Crianças com Câncer. Local em que os dois se apaixonam quando se conhecem nesse grupo. A narrativa é marcada por emoção, amor, alegria e dor.

O título do livro (The Fault in Our Stars, no original) nomeia o filme lançado em junho de 2014 e não deixa de ser uma alusão à citação da peça Júlio César, também conhecida como $A$ tragédia de Júlio César, de William Shakespeare. No diálogo entre Bruto e Cássio, na cena I, Ato II, a personagem responde à Bruto com a clássica frase shakesperiana : "The fault, dear Brutus, is not in our stars, / But in ourselves, that we are underlings" ("Há momentos em que os homens são donos de seus fados. Não é dos astros, caro Bruto, a culpa, mas de nós mesmos, se nos rebaixamos ao papel de instrumentos"). Além disso, Shakespeare é também citado por Anne Frank em seu diário: "Quem é tão firme que não possa ser seduzido?" (Greeen, 2012: 186).

Tanto o romance quanto o filme é uma autobiografia ficcional, cujo foco narrativo está em $1^{\text {a }}$ pessoa. $\mathrm{O}$ narrador-personagem é Hazel que transmite para a narrativa toda carga emocional através de uma linguagem informal.

\section{Cinema e Literatura: a construção das imagens}

Com a chegada do cinema, as pessoas passam a ter um novo acesso à arte, cujo público não é estabelecido pelo grau de compreensão do texto fílmico. O cinema consegue atingir a todo tipo de público através do recurso da imagem. Dessa 
forma, "gera uma nova forma de captar a realidade que responde às necessidades de um novo relacionamento entre 0 homem e o mundo" (Oliveira, 2000: 56).

No texto literário, o escritor precisa ser coerente e obter coesão para que a mensagem que é lida possa ser compreendida pelo leitor. Assim, ele cria imagens verbais que são capazes de fazer com que o leitor pense sobre aquilo que está lendo. Através da escrita, o autor pode deixar lacunas no texto que Iser vai chamar de lugar vazio. Nesse lugar, o leitor vai agir dentro do texto (Iser, 1999: 157).

Já a leitura fílmica é feita através das imagens concretas e em movimento. O leitor percebe o texto. O filme pode ser verbal ou não. Mas, o recurso para persuadir o leitor/espectador será a expressão dos atores na construção dessas imagens.

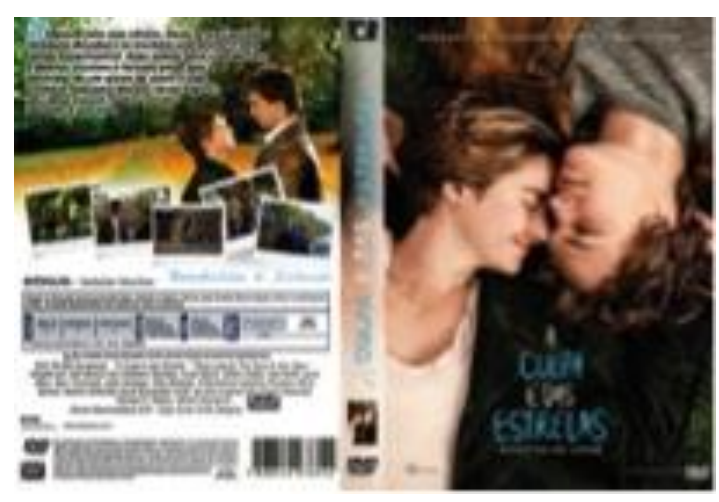

Fig. 2: Capa ilustrativa do filme The Fault in Our Stars. Direção: Josh Boone. Roteiro: John Green, Michael H. Weber. Estados Unidos: Distribuidor: Fox Film do Brasil, 2014. DVD (125min), dublado em Português.

Ismail Xavier observa que "a sucessão de imagens criadas pela montagem produz relações novas a todo instante e somos levados a estabelecer ligações propriamente não existentes na tela." (1988: 368).

Assim, o espectador deixa de ser apenas um leitor passivo das imagens para ser um leitor que conduz sua compreensão do texto através da construção das imagens da tela. 
Dessa forma, percebemos que a leitura dessas imagens feita através do olhar "não é imediata. Ela resulta de um processo onde intervêm não só as mediações que estão na esfera do olhar que produz a imagem, mas também aquelas presentes na esfera do olhar que as recebe. Este não é inerte, pois, armado, participa do jogo" (1988: 369).

A adaptação do texto literário $A$ culpa é das estrelas para o texto fílmico é feita pela direção de Josh Boone, à partir do roteiro feito por Scott Neustadter e Michael Webe. O título (The Fault in Our Stars, no original) é homônimo ao livro. Essa transposição é feita do hipotexto ao hipertexto.

Sobre o cinema e literatura, Maria de Lourdes Abreu de Oliveira revela que:

\begin{abstract}
Cinema e literatura não são a mesma coisa. Em princípio, enquanto o cinema trabalha com os meios de representação concretos, a literatura trabalha com abstrações. Apesar das diferenças, apresentam pontos de contato e podemos verificar que tanto o cinema apoia-se na literatura - a narrativa fílmica não só deve a Dickens, mas à ficção do século XIX e mesmo à da atualidade, alimentando-se, com fartura, especialmente no romance moderno - quanto a literatura também se apoia no cinema, recorrendo a processos tipicamente cinematográficos. Cinema e literatura permutam serviços $(2006,52)$.
\end{abstract}

Ao compararmos os dois textos, notamos que no filme há uma redução do número de personagens e de cenas. A supressão de algumas cenas e personagens no filme pode ser percebida pelos leitores do livro como, por exemplo: a visita que Hazel faz a Issac, a amizade que existe entre Hazel e Kaitlyn (personagem que não aparece no filme), a ex-namorada de Augustus (personagem que no livro recebe o nome de Caroline Mathers) e o momento em que Augustus e Hazel são impedidos pelos pais de irem ao porão da casa.

Se por um lado o filme reduz algumas cenas, por outro lado, além da música acrescida à obra, é criada uma atmosfera romântica ainda maior do que no livro, como podemos perceber desde o espaço físico do jantar que se difere do livro 
até mesmo na forma de expressão mais intensa dos sentimentos. Inevitavelmente, os leitores e espectadores se emocionam diante das imagens sugestivas que são construídas nas duas obras analisadas.

\section{A intermidialidade em a Culpa é das estrelas}

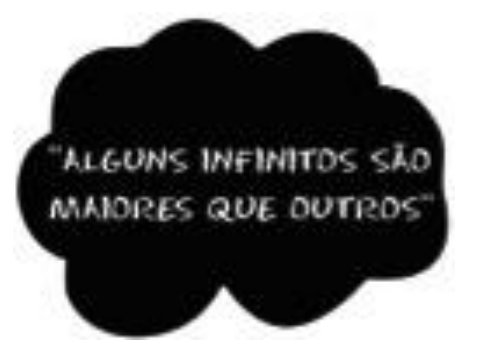

Fig. 3: Frase ilustrativa do filme e do livro A culpa é das estrelas.

Considerando a obra A culpa é das estrelas no ciberespaço, podemos encontrá-la em e-books, mas também fragmentada em jornais, blogs, Facebook e em outras redes sociais e suportes. De acordo com Heidrun Krieger Olinto, "as formas midiáticas funcionam como instrumentos de socialização e ganham importância crescente na encenação e na comunicação de sentimentos" (2002, p. 73). É natural que o leitor faça a utilização de trechos do livro acrescido de imagens do filme ou não. $E$ ainda, que ele se identifique com a obra a partir de um simples OK.

Pensar em literatura e internet significa pensar em hipermídia. No artigo intitulado Literatura e internet, Ana Cláudia Munari faz a seguinte consideração: “ A hipermídia é a convergência entre mídias, artes, gêneros, linguagens, textos e usuários no ciberespaço: ali, onde vídeos, imagens, música, fotografias, textos, podem ser postados, lidos, assistidos, compartilhados, linkados, traduzidos, recriados, versados, curtidos, comentados..."(http://ebooks.pucrs.br/edipucrs/anais/

XISemanaDeLetras/pdf/anamunari.pdf - Acesso em: 20/10/2014).

É possível que numa literatura imediatista o leitor se atenha apenas ao filme ou ao texto encontrado facilmente na internet 
ou na mídia. E ainda, que ele abandone as páginas do livro e se identifique com os fragmentos espalhados no ambiente virtual. Sobre a questão da internet, Ana Cláudia Munari continua dizendo que:

Em hipermídia, a literatura perde suas bordas, embaralha-se com as outras artes e linguagens do meio. Mais do que isso: compartilhada entre outros textos e agentes, geralmente fragmentada, ela não apenas perde o todo que o livro Ihe dá, entre capa e contracapa, como também embaça outra margem: entre autor e leitor (Ibidem).

De certa forma, a internet permitiu que A culpa é das estrelas perdesse o formato único de livro e de filme para adquirir outras formas, tais como: camiseta, caneca, botton, tênis e até arte para as unhas. Com isso, podemos perceber que a internet alargou a possibilidade de leitura e de recriação da produção literária da referida obra inicial.

\section{Considerações Finais}

De acordo com o objeto de estudo proposto, verifica-se que embora a obra de John Green em sua migração para o cinema mantenha pontos fiéis ao texto original, foi constatada a supressão de algumas informações e também o acréscimo de novos elementos ao texto fílmico.

Quando o texto A culpa é das estrelas é assistido no cinema e inserido na internet, além da relação intertextual que é estabelecida entre os textos e o texto original, ocorre consequentemente a intermidialidade. A internet além de funcionar como suporte de leitura digital no ciberespaço influenciou a reprodução literária da obra de Green. Mesmo sem papel, ela desconfigurou a forma do texto inicial dando a ele outro formato e utilidade para os leitores.

É possível encontrarmos inúmeros fragmentos e citações de $A$ culpa é das estrelas em diversos suportes, fontes e objetos. $E$ de quem seria a culpa da propagação do sucesso dessa obra no universo literário? A culpa desse sucesso seria de John Green? A culpa seria dos astros do cinema? Segundo 
Shakespeare: "The fault, dear Brutus, is not in our stars, / But in ourselves, that we are underlings". Sim, a culpa é de nós leitores e da nossa afetuosa recepção que damos a esse texto.

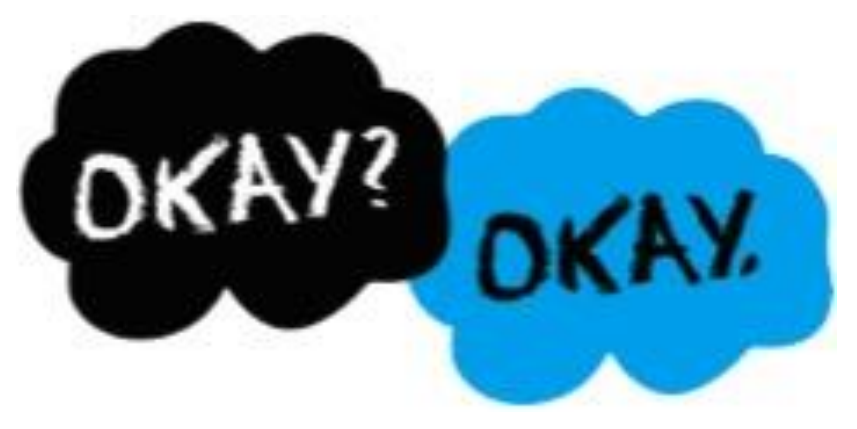

Fig. 4: Frase ilustrativa do filme The Fault in Our Stars. Direção: Josh Boone. Roteiro: John Green, Michael H. Weber. Estados Unidos: Distribuidor: Fox Film do Brasil, 2014. DVD (125min), dublado em Português.

\section{Referências}

Calvino, I. (2002). Seis propostas para o próximo milênio. Trad. Ivo Barroso. São Paulo: Companhia das Letras.

Green, J. (2012). A culpa é das estrelas. Trad. Renata Pettengill. Rio de Janeiro: Intrínseca.

Hall, S. (2005). A identidade cultural na pós-modernidade. Tradução de Tomaz Tadeu da Silva e Guacira Lopes Louro. 10 ed. Rio de Janeiro: DP\&A.

Iser, W. (1999). O ato da leitura v.2. $1^{\text {a }}$ edição. São Paulo: 34.

Lodge, D. (2009). A arte da ficção. Trad. Guilherme da Silva Braga. Porto Alegre: L\&PM Editores.

Lotman, Y. (1978). Estética e semiótica do cinema. Lisboa: Estampa. Mouren, Y. (1993). Le film comme hypertexte. Poétique, Paris: Seuil, n.93, 113-122.

Munari, A. Cláudia. Literatura e internet. In: http://ebooks.pucrs.br/edipucrs/anais/XISemanaDeLetras/pdf/anamun ari.pdf (acesso em: 20/10/2014).

Olinto, H. K. (2002). Processos midiáticos e comunicação literária. In: Olinto, H. K., Schollhammer, K. E. (orgs.). Literatura e mídia. Rio de Janeiro: Editora PUC-RIO. 
Oliveira, M. de L. A. (2000). Eros e Tanatos no universo textual de Camões, Antero e Redol. São Paulo: Annablume. . (2004). Literatura e cinema: uma questão de ponto de vista. Verbo de Minas: Letras, Juiz de Fora, v. 5, n.10, p.51-62, jan/jun/2005 (publicação interrompida). (2004). Literatura \& mídia: percursos perversos. Rio de Janeiro: Galo Branco.

Shakespeare, W. J. C. (1992). Trad. Carlos Lacerda. Rio de Janeiro: Bibliex.

Sklar, R. (1975). História social do cinema americano. Tradução de Octavio Mendes Cajado. São Paulo: Editora Cultrix.

Stam, R. (2006). Introdução à teoria do cinema. Tradução de Fernando Mascarello. 2 ed. Campinas, Papirus.

The Fault in Our Stars. Direção: Josh Boone. Roteiro: John Green, Michael H. Weber. Estados Unidos: Distribuidor: Fox Film do Brasil, 2014. DVD (125min), dublado em Português.

Xavier, I. (1988). In: Novaes, A. (org). O olhar. São Paulo: Companhia das letras. 